\title{
Economic Integration and the Core-Periphery Pattern: an Evolutionary Way to the Core
}

\author{
Volker Letzner* \\ University of Mainz
}

\begin{abstract}
The paper presents a core-periphery model with export fixed costs. Therefore it is possible to distinguish export and non-export firms and to determine four possible equilibria of regional allocation. The model predicts an evolutionary way to a more concentrated economic geography. (JEL Classification: F)
\end{abstract}

\section{Introduction}

An important aspect of economic integration - in particular the implementation of common markets - is the enablement of free factor mobility between the partner countries. To what extent can free factor mobility influence a firm's location decisions? Will a common market project establish and enforce a core-periphery-structure or will it decentralize the economic activities? In other words: will the European Internal Market be a "copy" of the US market which is characterized by a relatively concentrated industry? Will NAFTA force US-firms to move to Canada or to Mexico or will it enforce the existing "manufacturing" and "sun" belts? This paper affirms Krugman's answer [1991a and b] that further integration will enforce the

* Correspondence Address: Volker Letzner, University of Mainz, FB 03, D-55099 Mainz, Germany; Tel.: +49-6131-395595, Fax: +49-6131-395527

(C1996 - Institute for International Economics, Sejong Institution. All rights reserved. 
core. But his model predicts a "shocking" transformation process from decentralization to concentration. The paper shows that the existence of export fixed costs 〈as used by Venables [1994]〉 will slow down the concentration process: the core will be established evolutionary.

Section II presents the model and Section III analysis the regional allocation for different cases. A conclusion follows.

\section{The Model}

The model presents two identical countries (the home country $h$ and the foreign country $f$ ), each of them endowed with a fixed stock of workers producing varieties of good $x$, the differentiated or heterogeneous product. The consumers' preference for variety and economies of scale in the production of industrial goods is the reason for assuming monopolistic competition in this sector /see Dixit/Stiglitz [1977]). Two kinds of (industrial) firms will be considered: small firms $\left(n_{s}\right)$ that produce and sell only in the domestic market and large firms $\left(n_{1}\right)$ that produce in one country and sell their products in both countries. Depending on variable transportation costs and fixed export costs the number of the large/small firms can be determined endogenously.

Variable transportation costs (abbr. transportation or trade costs $\tau$ ) are real costs which result from crossing a border, that is, custom formalities, waiting periods and delays at the border. Fixed export costs $g$ 〈see Venables [1994]) arise to meet foreign standards, to establish a foreign distribution network et al.

\section{A. The Demand Side}

The utility function of $h$ is as follows and to avoid confusion the (identical) functions for $f$ are suppressed:

$$
U=X^{\mu} \cdot y^{1-\mu}
$$

where $y$ is the consumption of the homogeneous agricultural product and $X$ is the quantity index for all differentiated products, consumed home and produced home $\left(n=n_{1}+n_{s}\right)$ and abroad $\left(n_{1}\right) . \tau$ denotes transportation costs 
of the Samuelson iceberg-type, which are relevant for imported products and $\varepsilon$ is the elasticity of substitution among the products:

$$
X^{\frac{\varepsilon-1}{\varepsilon}}=\sum_{i=1}^{n_{1}+n_{s}} x_{i}^{\frac{\varepsilon}{\varepsilon-1}}+\sum_{j=1}^{n_{1}}\left(\tau^{-1} \cdot x_{j}^{*}\right)^{\frac{\varepsilon}{\varepsilon-1}}
$$

$Y_{h}$ is the (home) countries income and $p$ is the (firm's) price for each product. Now it is possible to derive 〈see Varian [1992]) the following demand functions:

$$
\begin{aligned}
& x=p^{-\varepsilon} \cdot\left[p^{1-\varepsilon} \cdot n+(p \cdot \tau)^{1-\varepsilon} \cdot n_{1}\right]^{-1} \cdot \mu \cdot Y_{h} \\
& x^{*}=p^{-\varepsilon} \cdot \tau^{1-\varepsilon} \cdot\left[p^{1-\varepsilon} \cdot n+(p \cdot \tau)^{1-\varepsilon} \cdot n_{1}\right]^{-1} \cdot \mu \cdot Y_{h}
\end{aligned}
$$

\section{B. The Supply Side}

Every country is endowed with sectoral (and in the short term also national) immobile workers who produce heterogeneous products; following Krugman [1991 $b$ ] it is useful to normalize the total stock of labor as $L=L_{h}+L_{f}=\mu$ and the nominal wage to unity. Constant marginal costs c and production fixed costs $f$ characterize the production function. It is usual to assume monopolistic competition in the case of economies of scale and the "love for variety"-utility function. This results in monopolistic profit maximization (price $>$ marginal revenue $=$ marginal cost) and a zero-profit condition (price $=$ average cost).

The first condition is:

$$
p-c=\frac{c}{\varepsilon-1} \text { or } p=c \cdot\left(1+\frac{1}{\varepsilon-1}\right)=\frac{c \cdot \varepsilon}{\varepsilon-1}
$$

where $-\varepsilon$ is the elasticity of demand, which is constant for a sufficiently large number of firms.

The zero-profit condition is different for the two types of firms:

- a small firm - facing production fixed cost $f$ - produces and sells $x$ in one country

- a large firm - facing production and export fixed costs $f+g$ - produces $x+x^{*}$ in one country and exports $x^{*}$ to the other country.

With $\theta=n_{1} / n$ there are two possible combinations in each country: 
Table 1

Equation (6)

\begin{tabular}{|cc|c|c|}
\hline & & $(p-c) \cdot\left(x+x^{*}\right)-(f+g)$ & $(p-c) \cdot x-f$ \\
\hline (6a) & $\theta=0$ & $<0$ & $=0$ \\
\hline (6b) & $\theta=1$ & $=0$ & $<0$ \\
\hline
\end{tabular}

With the simple sub-utility function $X$ used here it is not possible to get a stable interior solution $0<\theta<1$. In order to model this more general result see Venables [1994].

\section{Market Equilibrium}

Because of symmetry one countries expenditure for industry goods equals the industries receipts:

$$
n \cdot \theta \cdot p \cdot\left(x+x^{*}\right)+n \cdot(1-\theta) \cdot p \cdot x=\mu \cdot Y_{h}
$$

where the first term is the large firms' revenue at home and abroad and the second term denotes the small firms' revenue. From (6) in (7) follows:

$$
\begin{aligned}
& \left.n\right|_{\theta=1}=\frac{\mu \cdot Y}{(g+f) \cdot \varepsilon} \\
& \left.n\right|_{\theta=0}=\frac{\mu \cdot Y}{f \cdot \varepsilon}
\end{aligned}
$$

So the number of firms rises for falling fixed cost (production and possible export fixed cost) and/or falling $\varepsilon$ which symbolizes lower economies of scale. The reason for the first effect is as follows: lower fixed cost free resources that are used - following the consumers preference for choice to establish new varieties ( $=$ new firms) and not to expand the output per firm. The second effect rises because these models of monopolistic competition connect the demand and the supply side in a way that the elasticity of substitution $\varepsilon$ determines the economies of scale: little $\varepsilon$ means that the products are difficult to substitute each other and the preference for choice is high; therefore $\varepsilon$ signalize the consumers' willingness to pay high markups over marginal cost to get more varieties with a lower output per firm.

Let us summarize the two symmetric situations (named as III and IV for further purpose): 


\section{Table 2}

\section{Decentralization}

\begin{tabular}{|c|c|c|c|c|c|c|c|}
\hline Situation & & \multicolumn{3}{|c|}{ Home Country } & \multicolumn{3}{c|}{ Foreign Country } \\
\hline & & $L$ & $Y$ & $n$ & $L$ & $Y$ & $n$ \\
\hline \multirow{2}{*}{ III } & \multirow{2}{*}{$\theta=1$} & $\mu / 2$ & 0.5 & $\frac{\mu \cdot 0.5}{(g+f) \cdot \varepsilon}$ & $\mu / 2$ & 0.5 & $\frac{\mu \cdot 0.5}{(g+f) \cdot \varepsilon}$ \\
\hline IV & \multirow{2}{*}{$\theta=0$} & $\mu / 2$ & 0.5 & $\frac{\mu \cdot 0.5}{f \cdot \varepsilon}$ & & 0.5 & $\frac{\mu \cdot 0.5}{f \cdot \varepsilon}$ \\
\hline
\end{tabular}

\section{Regional Allocation}

\section{A. Overview}

This section discusses the basic model in a spatial environment. International mobility of workers is allowed and concentration processes are possible. The procedure of the chapter is orientated around Krugman's [1991a, b] suggestions: are there real wage differentials, which lead to a industrial core? Krugman discussed two possibilities: decentralization or centralization. Now it is possible to consider three situations: decentralization, total and partial concentration. A similar table as above will illustrate the difference, where for historical accident - the home country attracts the industry; concentration in the foreign country is possible as well but not further discussed:

Table 3

Total Centralization

\begin{tabular}{|c|c|c|c|c|c|c|c|}
\hline Situation & & \multicolumn{3}{|c|}{ Home Country } & \multicolumn{3}{c|}{ Foreign Country } \\
\hline & & $L$ & $Y$ & $n$ & $L$ & $Y$ & $n$ \\
\hline $\mathrm{I}$ & $\theta=1$ & $\mu$ & $\frac{1+\mu}{2}$ & $\frac{\mu}{(g+f) \cdot \varepsilon}$ & 0 & $\frac{1-\mu}{2}$ & $\frac{\mu}{(g+f) \cdot \varepsilon}$ \\
\hline $\begin{array}{c}\mathrm{V} \\
\text { (instable) }\end{array}$ & $\theta=0$ & $\mu$ & $\frac{1+\mu}{2}$ & $\frac{\mu}{f \cdot \varepsilon}$ & 0 & $\frac{1-\mu}{2}$ & $\frac{\mu}{f \cdot \varepsilon}$ \\
\hline
\end{tabular}

Note that situation I is the "Krugman-Case" and that situation V is instable, because there are no industrial goods available in the foreign country. Partial concentration is characterized by a special firm-type pattern: one country has export firms, while the other does not: 
Table 4

Partial Centralization

\begin{tabular}{|l|c|c|}
\hline Situation & Home country $(\theta=1)$ & foreign country $(\theta=0)$ \\
\hline \multirow{3}{*}{ II } & $\frac{1-\mu}{2}<\mathrm{Y}<\frac{1+\mu}{2}$ & $0<L<\mu$ \\
& $0<n<\frac{\mu}{(f+g) \cdot \varepsilon}$ & $\frac{1-\mu}{2}<\mathrm{Y}<\frac{1+\mu}{2}$ \\
\hline & \multicolumn{2}{|c}{$\mid \frac{\mu}{f \cdot \varepsilon}$} \\
\hline
\end{tabular}

So far the analysis showed that positive export fixed costs $\mathbf{g}>\mathbf{0}$ already have importance. Krugman [1991a, b] discussed two regional allocation areas: concentration or deconcentration, which are our cases I or III. Now, this number will double. Along with this it is possible to show that positive export fixed cost slow down the adjustment of international factor allocation necessary after an integration step. First, let us consider two initial situations of regional allocation:

\section{B. Situation III: Concentration of All Firms in One Country + Only Large Firms}

All workers and firms are in the home country and $\theta=1$. This situation would be stable if there are no incentives to start production in the other country founding a large or small firm and earning a positive profit. So it must be proved whether $\pi^{1 d}$ and/or $\pi^{s d}>0$ or not (ld for a large defecting firm, $s d$ for a small defecting firm and $n$ for a non-defecting firm). A defecting firm - Krugman: a firm that starts production in the other country - has to attract workers to produce in the partner country and the workers must be compensated for the fact that they have to import all $(n-1)$ varieties and to pay the transportation costs. Therefore the defecting firm has to pay wages $\tau^{\mu}$ times higher than the wages at home; with the constant real markup it follows that the prices charged by the defecting firm are higher as well. Let us denote the sales of a non-defecting firm as $E^{\ln }$ ( $l n$ for large nondefecting) and that of a large respective small defecting firm as $E^{1 d}, E^{\text {sd }}$. It is possible to show (see Appendix A1), that the profits of a defecting firm are positive if and only if: 


$$
\begin{aligned}
& v^{1} \equiv \frac{E^{1 d}}{E^{l n}}-\tau^{\mu}=0.5 \cdot \tau^{\mu \cdot(1-\varepsilon)} \cdot\left[(1+\mu) \cdot \tau^{1-\varepsilon}+(1-\mu) \cdot \tau^{\varepsilon-1}\right]-\tau^{\mu}>0 \\
& v^{s} \equiv \frac{E^{s d}}{E^{l n}-\varepsilon \cdot g}-\tau^{\mu}=0.5 \cdot \tau^{\mu \cdot(1-\varepsilon)} \cdot\left(1-\frac{g}{f+g}\right)^{-1}(1-\mu) \cdot \tau^{\varepsilon-1}-\tau^{\mu}>0
\end{aligned}
$$

If $v>(<) 0$, the firm will (not) move; so the critical value of $v=0$ has to be considered. Examination of $v^{1}$ shows that it is independent of $g$ (and $f$ ), because $g+f$ is relevant for every large (defecting or not defecting) firm, so:

$$
\left.\tau\right|_{v^{1}=0}=\tau(\mu, \varepsilon)
$$

with $\left.\frac{d g}{d \tau}\right|_{v^{1}=0}=\infty$

Appendix A2 shows the derivation of (13):

$$
\left.g\right|_{v^{s}=0}=\frac{f}{\left(1-0.5 \cdot \tau^{-\mu \cdot \varepsilon+\varepsilon-1} \cdot(1-\mu)\right)^{-1}-1}
$$

with $\left.\frac{d g}{d \tau}\right|_{v^{s}=0}<0$ for $\mu<\frac{\varepsilon-1}{\varepsilon}$

Now it is possible to evaluate parameter constellations, which allow that only small firms will defect and large firms will stay in the home country. Two results are possible: either there are only large firms in $\mathrm{h}$ and small firms in $\mathrm{f}$ or there are only small firms in $f$ and $h$ - a possibility that cannot be ruled out yet and has to be considered in more detail. Therefore another starting point is postulated.

\section{Situation IV: Decentralization of Small Firms}

Assume that all workers and firms are similarly distributed over $f$ and $h$ with $\theta=0$ and $\pi^{s}=0$. Is it now profitable to expand and to establish an "export department" and to mutate from a small to a large firm? Is it possible for a expanding firm ( $s l$ for "small $\rightarrow$ large") to earn $\pi^{s l}>0$ ? The costs of this decision are $g$ and no increase of production fixed and variable costs because the firm's influence on the labor and goods markets is negligible. Appendix 3 shows that $\pi^{1}>\pi^{s}=0$ holds, if and only if:

$$
v^{s l} \equiv f \cdot \tau^{1-\varepsilon}-g>0
$$


$v=0$ is again the critical value, when a firm is indifferent between establishing an export department or not:

$$
\left.g\right|_{v^{s}=0}=f \cdot \tau^{1-\varepsilon}
$$

with $\left.\frac{d g}{d \tau}\right|_{v^{l}=0}<0$

\section{Different Areas of Regional Allocation}

Now it is possible to use a $\tau-v$-diagram to interpret the equations (10), (11) and (14) and to use a $\tau$-g-diagram to interpret the equations (12), (13) and (15). The following figures are calculated for $\mu=0.3, \varepsilon=4$ and $f=0.9$ to show all relevant areas:

Area I: only large firms are concentrated in one country

Area II: only large firms in one and only small firms in the other country Area III: only large firms in both countries Area IV: only small firms in both countries

\section{Figure 1}

\section{$\tau$-g-Diagram}

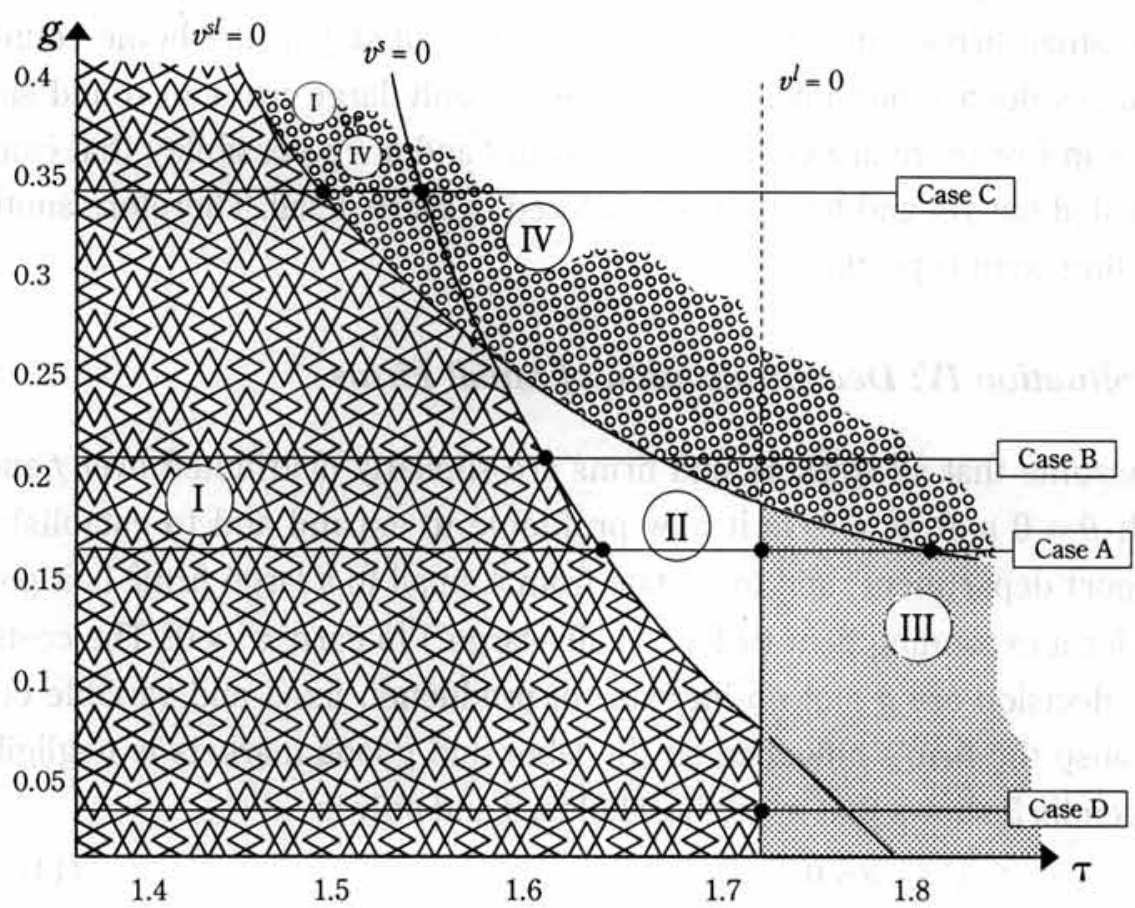


Figure 2

\section{$\tau$ - $\nu$-Diagram}
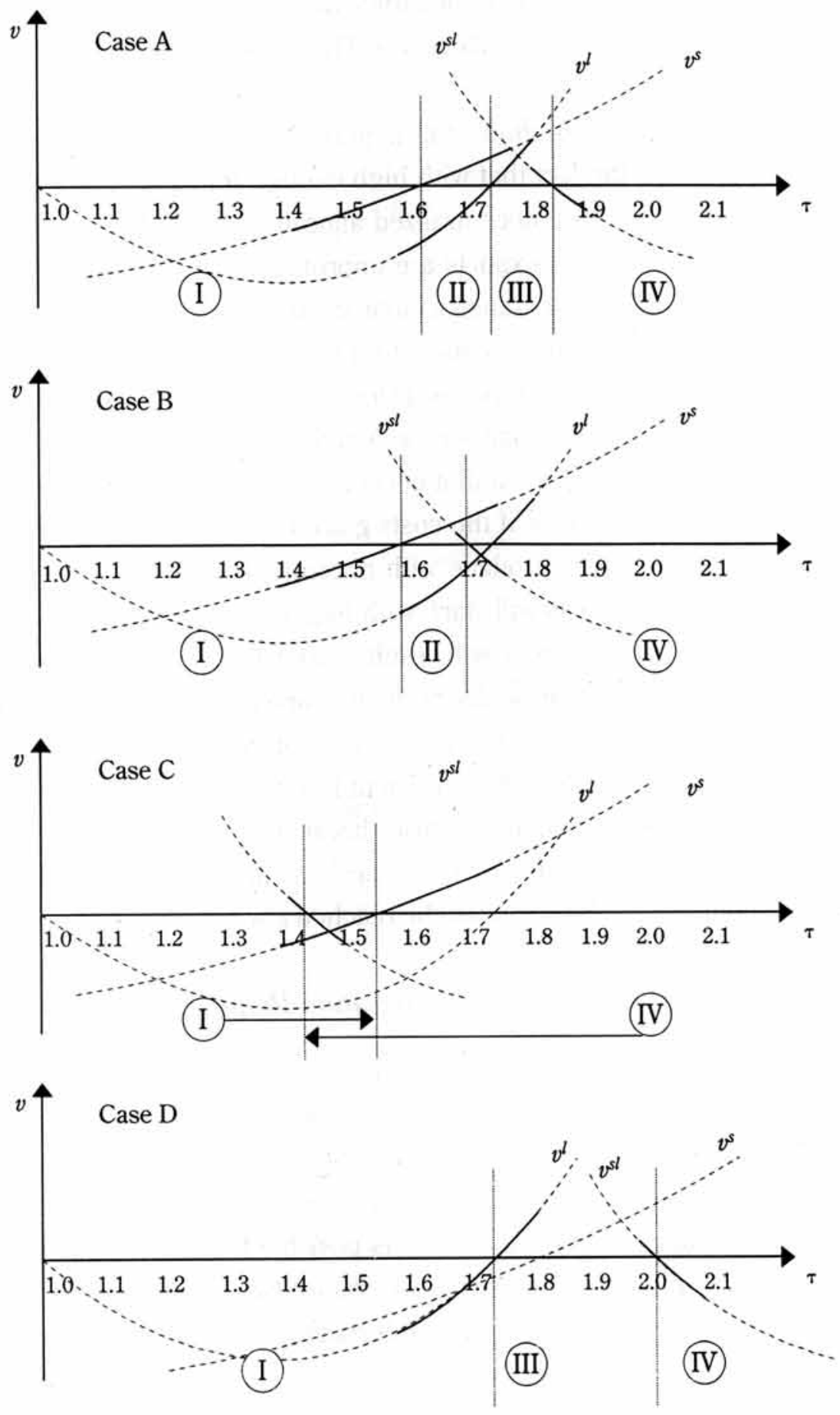
The analysis has shown that the assumption of positive $g$ is a necessary (for $g=0$ the horizontal axis of fig. 1 shows the Krugman-Case, which includes only area I and III), but not sufficient condition for the possibility of at least four areas of industry allocation. The existence of other areas can and should not be ruled out.

Area IV: Equation (15) shows the hyperbolically shape of the $v^{s l}=0-$ curve and therefore the fact that with high enough transport costs the area IV is always relevant. So a decentralized allocation of small firms for high transportation costs exists: exports are unprofitable in this case. This area will be smaller the lower the transportation costs are.

A reduction of the transport costs until the point where the $v$-curve of figure 2 crosses the horizontal axis has different results which depend on the value of $g$. If $g$ is relatively small - case A and D - it will be profitable (see equation (14)) to start export until a decentralized allocation of big firms is reached: area III. Otherwise if the costs g are relatively high - case B and $\mathrm{C}$ - it will be too costly to produce with decentralized firms and to export and a concentration process will start: with high export costs the concentration of big firms in one country will result - area I. Assuming middle high costs $g$ (case B) the asymmetric distribution of area II will be relevant. This area will be left, when further reductions of $\tau$ allow only the concentrated production by big firms. Note that sufficient low trade costs are still responsible for a total concentration of industries because equation (15) shows that the crossing point of the $v$-curve with the ordinate arises with $f=g$. Because of the assumption $g<f$ the area I will be reached always.

\section{E. Total Analysis: Integration and Migration Requirements}

So far the analysis has described different areas of international allocations dependent on different parameter constellations. Now the area for the asymmetric distribution of industries will be considered in more detail: when will there only be large firms in the home country and only small firms in the foreign country? As such it is possible to describe exactly the distribution of workers and industries. Therefore two definitions are necessary, where $L$ is the total amount of the international mobile workers:

$$
L_{h}+L_{f} \equiv \mu
$$




$$
\varphi \equiv \frac{L_{h}}{\mu}=\frac{L_{h}}{L_{h}+L_{f}}
$$

The following procedure produces the same results as above but uses another analytical method. The question above was as follows: is it profitable to move into the other country and to pay the migrating workers higher wages? The question now is: what is the ratio of the real wages $\omega \equiv \frac{\omega_{l}}{\omega_{\text {, }}}$ for different distributions of workers from $\varphi=1$ (all workers in h) over equal distribution $\varphi=0.5$ to the situation where no more workers remain in $\mathrm{h}(\varphi=0)$ ? This ratio determines the migration decisions of the workers who follow the higher real wages.

Note that the long-term character of this model does not distinguish between these two questions. It is wrong to ask whether the location decisions of the firms determine the migration streams or vice versa that workers' migration decisions determine the allocation of industries, because both questions are actually two sides of one coin: economic activity settles where it is (more) profitable.

Figure 3 - see the original figure, Krugman [1991b], p.493 - helps to understand the following analytical procedure:

Figure 3

Real Wage Ratios

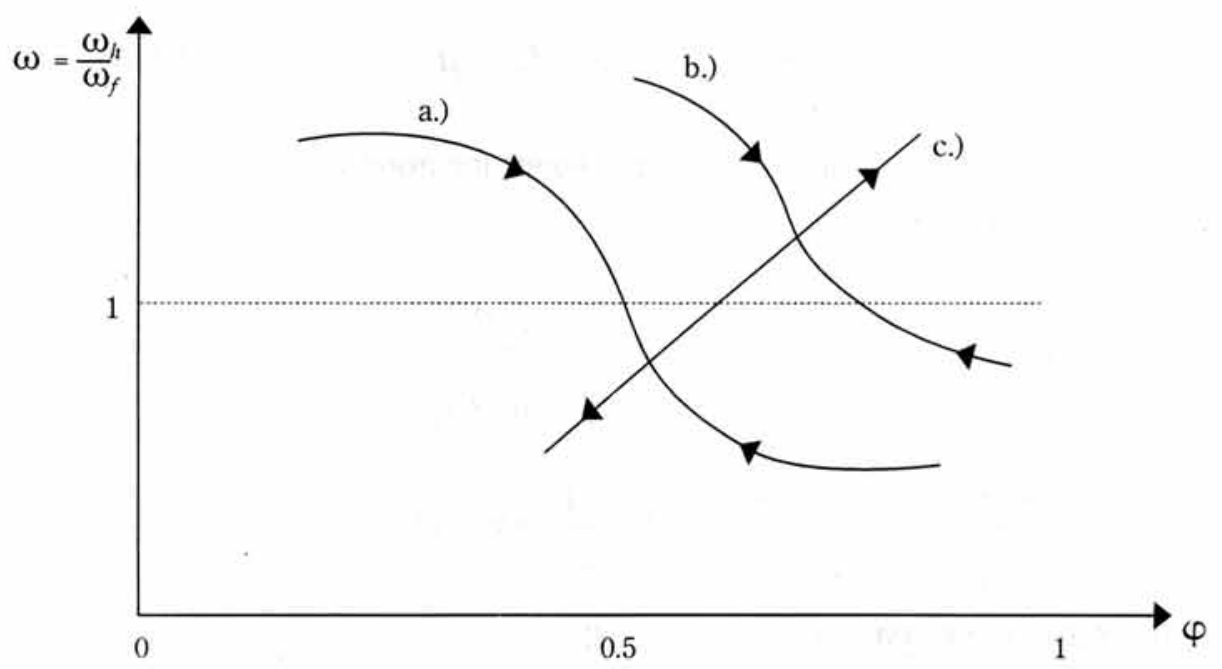


The curve a.) shows that - independent of an accidental starting point - a long-run equilibrium with an equalized distribution of the workers will be reached because the less (more) populated country is able to pay a higher (smaller) real wage and therefore the workers will immigrate (emigrate). Similar argumentation postulates for case b.) a stable allocation with higher - whatever the reasons are - population in $h$. But every curve with positive sharp at $\omega=1$ shows the instability of this allocation and a small shock is sufficient to start migrations to one of the both countries. Other curves are possible and can be likewise interpreted; in particular, the existence of curves with multiple - stable or unstable - equilibria is possible.

The following steps require the explicit consideration of the nominal wages $w$ that could be standardized to unity until now and it is necessary to redefine the parameters $f, g$ and $c$ and to measure in real labor units; the interpretation remains unchanged. Let us consider the situation $\theta_{h}=1$ and $\theta_{f}=0$ which characterizes the area II.

$$
\begin{array}{ll}
n_{h}=\frac{\mu \cdot \varphi}{(g+f) \cdot \varepsilon} & n_{f}=\frac{\mu \cdot(1-\varphi)}{f \cdot \varepsilon} \\
x_{h}+x_{f}^{*}=\frac{(\varepsilon-1) \cdot(f+g)}{c} & x_{f}=\frac{(\varepsilon-1) \cdot f}{c} \\
p_{h}=w_{h} \cdot c \cdot \frac{\varepsilon}{\varepsilon-1} & p_{f}=w_{f} \cdot c \cdot \frac{\varepsilon}{\varepsilon-1} \\
w_{h} \cdot L_{h}=\mu \cdot\left[Y_{h}+\left(1-\delta_{f}\right) \cdot Y_{f}\right] & w_{f} \cdot L_{f}=\mu \cdot \delta_{f} \cdot Y_{f}
\end{array}
$$

where $\delta$ is the share of income which is spent for goods consumed and produced in the same country:

$$
\begin{array}{ll}
\delta_{h}=1 & \delta_{f}=\frac{p_{f}^{\frac{1}{1-\varepsilon}} \cdot n_{f}}{p_{f}^{\frac{1}{1-\varepsilon}} \cdot n_{f}+\left(p_{h} \cdot \tau\right)^{\frac{1}{1-\varepsilon}} \cdot n_{h}} \\
Y_{h}=\frac{1-\mu}{2}+w_{h} \cdot \varphi \cdot \mu & Y_{f}=\frac{1-\mu}{2}+w_{f} \cdot(1-\varphi) \cdot \mu
\end{array}
$$

and the ratio of the real wages follows as: 


$$
\omega \equiv \frac{\omega_{h}}{\omega_{f}}=\frac{w_{d} \cdot\left[p_{f}^{1-\varepsilon} \cdot n_{f}+\left(p_{h} \cdot \tau\right)^{1-\varepsilon} \cdot n_{h}\right]^{\mu}}{w_{p} \cdot\left(p_{f}^{1-\varepsilon} \cdot n_{f}\right)^{\mu}}
$$

The equations (16) and (18) to (21) determine simultaneously the nominal wages necessary for labor market equilibrium in $h$ and $f$ and can be calculated by numerical methods. The real wages and its ratio are calculated straightforwardly.

From part 2.4 above it is known which critical value $\tau^{*}$ has to be fallen short of to reach the area II with asymmetric allocation (see case $A$ or $B$ ); for $g=0.2$ holds $\tau^{*} \approx 1.7$ and for this and smaller trade costs the following figure 4 for the ratio of the real wages arises:

\section{Figure 4}

\section{Real Wage Ratios: Area II}

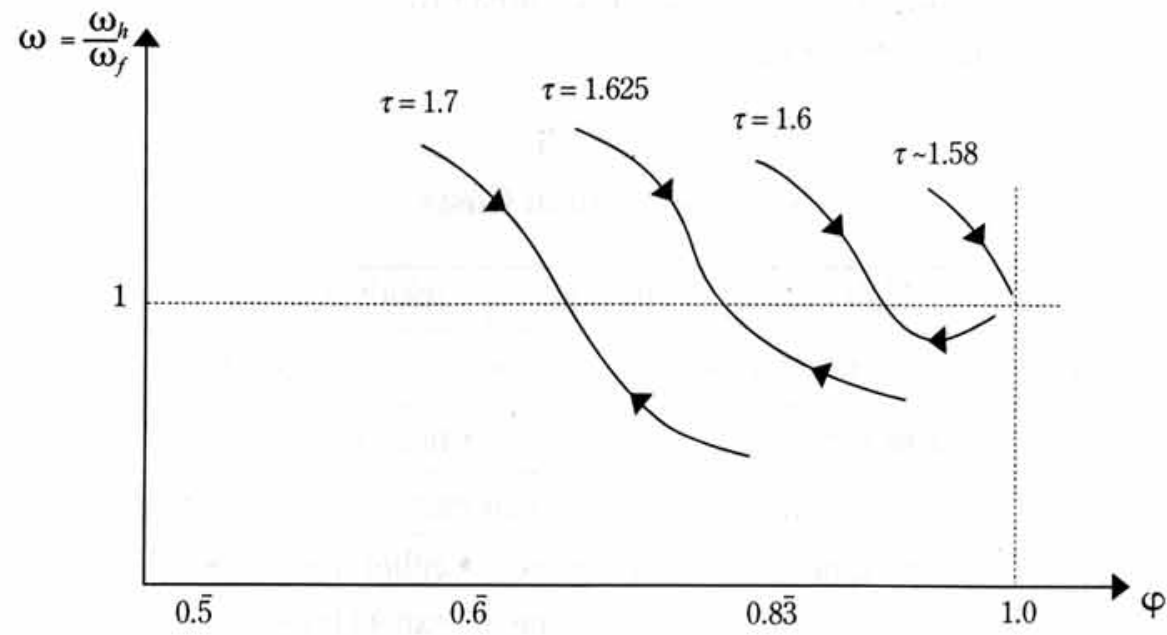

The interpretation of this figure is: A integration process lowers the transport costs and if a critical value is fallen short of, a concentration process will start and will change the workers distribution from $50 \%$ in each country to $\varphi=1$ (or $\varphi=0$ analogous) - thus Krugman's [1991b] result. Now this analysis shows that this national reallocation of factors does not have to be as crass as in the Krugman case: when the transport costs reach their critical value, not all firms will leave one country, but rather, the small firms remain and continue to employ workers (about $30 \%$ in the example above). 
Further integration steps (= falling transport costs) shifts the $\omega$-curve to the right and shows that the migration requirements are reduced: the number of workers and of small firms in the peripheral country shrinks slowly until eventually the situation $\varphi=1$ (or $\varphi=0$ respectively) is reached.

The intention of this paragraph was to show that the existence of positive export costs may reduce the migration requirements entailed by economic integration.

\section{Conclusion}

The previous chapters showed that positive fixed export costs influence the core-periphery pattern of cconomic activity. So Krugman's main contribution - pecuniary externalities drive the core-periphery pattern - is still at work, the analysis shows that it is possible to get a much more realistic result: export and non-export firms are distinguishable, the number of possible equilibria doubles to four and the concentration process slows down. The following table illustrates the results:

\section{Table 5}

\section{Transportation Costs}

\begin{tabular}{|c|c|c|c|c|}
\hline & high & high-middle & middle-low & low \\
\hline \multirow{2}{*}{$\begin{array}{l}\text { no export } \\
\text { fixed costs }\end{array}$} & \multicolumn{2}{|c|}{ decentralization } & \multicolumn{2}{|c|}{ concentration } \\
\hline & \multicolumn{2}{|c|}{ - firms in both countries } & \multicolumn{2}{|c|}{ - firms in one country } \\
\hline \multirow[b]{2}{*}{$\begin{array}{l}\text { with export } \\
\text { fixed costs }\end{array}$} & decentralization & \multicolumn{2}{|c|}{ partial concentration } & total concentration \\
\hline & $\begin{array}{l}\text { - non-export } \\
\text { firms in both } \\
\text { countries (IV) }\end{array}$ & $\begin{array}{l}\text { - export firms } \\
\text { in both coun- } \\
\text { tries (III) }\end{array}$ & $\begin{array}{l}\text { - either has } \\
\text { export firms, } \\
\text { while the } \\
\text { other does } \\
\text { not (II) }\end{array}$ & $\begin{array}{l}\text { - either has } \\
\text { export firms, } \\
\text { while the } \\
\text { other has no } \\
\text { firms (I) }\end{array}$ \\
\hline
\end{tabular}

The model supports the prediction that falling transportation costs because of technical progress or further integration steps - will enforce the core-periphery pattern of regional or world economic geography. But this concentration process will be "slowly" and evolutionary. 


\section{Appendix}

Notation:
$h$ : home country
f. foreign country
$l$ : large firm
s: $\quad$ small firm
$d$ : defecting firm
$n$ : $\quad$ non-defecting firm

\begin{tabular}{|l|c|c|c|}
\hline $\begin{array}{c}\text { (for a initial con- } \\
\text { centration of large } \\
\text { firms in } h \text { ) }\end{array}$ & $\begin{array}{c}\text { large non- } \\
\text { defecting firm }(l n) \\
\text { (producing in } h \text { ) }\end{array}$ & $\begin{array}{c}\text { large defecting } \\
\text { firm }(l d) \\
\text { (producing in } f \text { ) }\end{array}$ & $\begin{array}{c}\text { small defecting } \\
\text { firm }(s d) \\
\text { (producing in } f \text { ) }\end{array}$ \\
\hline sales in $h$ & $x^{n}$ & $x^{d^{*}}$ & 0 \\
\hline sales in $f$ & $x^{n^{*}}$ & $x^{d}$ & $x^{d}$ \\
\hline sum of sales & $x^{l n}=x^{n}+x^{n^{*}}$ & $x^{l d}=x^{d}+x^{d^{*}}$ & $x^{l d}=x^{d}$ \\
\hline value in $h$ & $E^{n}$ & $E^{d^{*}}$ & 0 \\
\hline value in $f$ & $E^{n^{*}}$ & $E^{d}$ & $E^{d}$ \\
\hline sum of values & $E^{l n}=E^{n}+E^{n^{*}}$ & $E^{l d}=E^{d}+E^{d^{*}}$ & $E^{l d}=E^{d}$ \\
\hline profits & $\pi^{l n}=0$ & $\pi^{l d}$ & $\pi^{s d}$ \\
\hline
\end{tabular}

\begin{tabular}{|l|c|c|}
\hline $\begin{array}{c}\text { (for a initial de- } \\
\text { centralization of } \\
\text { small firms) }\end{array}$ & $\begin{array}{c}\text { small firm }(s) \\
\text { (producing in } i=h, f)\end{array}$ & $\begin{array}{c}\text { large expanding } \\
\text { firm (sl) } \\
\text { (producing in } i=h, f \text { ) }\end{array}$ \\
\hline sales in $i$ & $x$ & $x$ \\
\hline sales in $j=h, f \neq i$ & 0 & $x^{*}$ \\
\hline sum of sales & $x^{s}=x$ & $x^{s l}=x^{*}+x$ \\
\hline value in $i$ & $E$ & $E$ \\
\hline value in $j=h, f \neq i$ & 0 & $E^{*}$ \\
\hline sum of values & $E^{s}=E$ & $E^{l d}=E+E^{*}$ \\
\hline profits & $\pi^{s}=0$ & $\pi^{s l}$ \\
\hline
\end{tabular}

\section{A1. Ad Equation (10) and (11):}

\section{Step}

The profit of a large defecting firm is positive, if:

$$
\pi^{l d}=\left(x^{d}+x^{d^{*}}\right) \cdot p \cdot \tau^{\mu}-\left(x^{d}+x^{d^{*}}\right) \cdot c \cdot \tau^{\mu}-(f+g) \cdot \tau^{\mu}>0
$$




$$
\Leftrightarrow\left(x^{d}+x^{d^{*}}\right) \cdot p-\left(x^{d}+x^{d^{*}}\right) \cdot c-(f+g)>0
$$

Because of the zero profit condition for a non defecting firm holds:

$$
\pi^{l n}=x^{l n} \cdot p-x^{l n} \cdot c-(f+g)=0
$$

Compare (A3) with (A2) and the result shows that (A1) holds, if:

$$
\begin{aligned}
& x^{d}+x^{d^{*}}>x^{l n} \\
& \Leftrightarrow \tau^{\mu} \cdot p \cdot\left(x^{d}+x^{d^{*}}\right)>\tau^{\mu} \cdot p \cdot x_{a}
\end{aligned}
$$

which is by definition (value = price times sales) and by the fact, that abroad the price is $\tau^{\mu}$ times higher than at home:

$$
E^{l d}>\tau^{\mu} \cdot E^{l n}
$$

So, (A1) holds, if:

$$
v^{1} \equiv \frac{E^{l d}}{E^{\ln }}-\tau^{\mu}>0
$$

\section{Step}

The profit of a small defecting firm is positive, if:

$$
\begin{aligned}
& \pi^{s d}=x^{d} \cdot p \cdot \tau^{\mu}-x^{d} \cdot c \cdot \tau^{\mu}-f \cdot \tau^{\mu}>0 \\
& \Leftrightarrow x^{d} \cdot p-x^{d} \cdot c-f>0 \\
& \Leftrightarrow x^{d}>\frac{f}{(p-c)}
\end{aligned}
$$

For the non defecting firm follows from (A3):

$$
x^{\ln }-\frac{g}{(p-c)}=\frac{f}{(p-c)}
$$

Comparison of (A11) with (A10) yields that (A8) holds, if:

$$
\begin{aligned}
& x^{d}>x^{\ln }-\frac{g}{(p-c)} \\
& \Leftrightarrow \tau^{\mu} \cdot p \cdot x^{d}>\tau^{\mu} \cdot p \cdot x^{\ln }-\tau^{\mu} \cdot p \cdot \frac{g}{p-c}
\end{aligned}
$$

because of $\frac{g}{p-c}=\varepsilon$ follows: 


$$
\Leftrightarrow v^{s} \equiv \frac{E^{s d}}{E^{\ln }-\varepsilon \cdot g}-\tau^{\mu}>0
$$

\section{Step}

It is now necessary to calculate the firms values for the different situations; because there are no savings, it is simple to solve the problem for the initial situation: the total income of both nations is used for the purchase of agricultural and industrial goods, so the income which is spent for differentiated products per firm is:

$$
E^{\ln } \equiv \frac{\mu}{n} \cdot\left(Y_{h}+Y_{f}\right)=\frac{\mu}{n}\left(\left(\frac{1-\mu}{2}+\frac{\mu}{2}+\frac{\mu}{2}\right)+\frac{1-\mu}{2}\right)=\frac{\mu}{n}
$$

To solve the problem for the defecting firms it is necessary to use the demand functions: what are the quantities of products that are sold by defecting firms, what is $x^{d}$ and $x^{d^{*}}$ ? Both are functions of the price $p \cdot \tau^{\mu}$, which, compared to the homeland price, is higher; the demand functions yield:

$$
\begin{aligned}
& x^{d}=p^{-1} \cdot \tau^{-\mu \cdot \varepsilon+\varepsilon-1} \cdot n^{-1} \cdot \mu \cdot Y_{f} \\
& x^{d^{*}}=p^{-1} \cdot \tau^{-\mu \cdot \varepsilon-\varepsilon+1} \cdot n^{-1} \cdot \mu \cdot Y_{h}
\end{aligned}
$$

So the values of the defecting firms are:

$$
\begin{aligned}
& E^{d}=E^{s d}=p \cdot \tau^{\mu} \cdot x^{d}=\left(\frac{\tau^{\mu}}{\tau}\right)^{1-\varepsilon} \cdot \frac{\mu}{n} \cdot Y_{f} \\
& E^{d^{*}}=p \cdot \tau^{\mu} \cdot x^{d^{*}}=\left(\tau^{\mu} \cdot \tau\right)^{1-\varepsilon} \cdot \frac{\mu}{n} \cdot Y_{h} \\
& E^{l d}=E^{d}+E^{d^{*}}=\frac{\mu}{n} \cdot\left[\left(\tau^{\mu+1}\right)^{1-\varepsilon} Y_{h}+\left(\tau^{\mu-1}\right)^{1-\varepsilon} \cdot Y_{f}\right]
\end{aligned}
$$

With $Y_{h}=(1+\mu) / 2$ and $Y_{f}=(1-\mu) / 2$ substitute (A18) - (A20) in (A7) and (A14) and get:

$$
\begin{aligned}
& v^{l}=0.5 \cdot \tau^{\mu \cdot(1-\varepsilon)} \cdot\left[(1+\mu) \cdot \tau^{1-\varepsilon}+(1-\mu) \cdot \tau^{\varepsilon-1}\right]-\tau^{\mu} \\
& v^{s}=0.5 \cdot \tau^{\mu \cdot(1-\varepsilon)} \cdot\left(1-\frac{g}{f+g}\right)^{-1}(1-\mu) \cdot \tau^{\varepsilon-1}-\tau^{\mu}
\end{aligned}
$$


With $Y_{h}=1$ equation (9) shows that the number of firms at home is $n=$ $\mu /((f+g) \cdot \varepsilon)$; this is used to derive (11).

\section{A2. Ad Equation (13) and It's Derivation}

$$
\begin{aligned}
& v^{s}=0, \text { for } \frac{\tau^{\mu-\mu \cdot \varepsilon}(1-\mu) \cdot \tau^{\varepsilon-1}}{\tau \cdot\left(1-\frac{g}{f+g}\right)}=\tau^{\mu} \\
& \Leftrightarrow \tau^{-\mu \cdot \varepsilon+\varepsilon-1}(1-\mu)-2=-2 \cdot \frac{g}{f+g} \\
& \Leftrightarrow\left(0.5 \cdot \tau^{-\mu \cdot \varepsilon+\varepsilon-1}(1-\mu)+1\right)^{-1}=\frac{f}{g}+1 \quad \Leftrightarrow \quad(13) \\
& \left.\frac{d g}{d \tau}\right|_{v^{s}=0}=-\frac{g^{2}}{f} \cdot \frac{0.5 \cdot(1-\mu) \cdot(-\mu \cdot \varepsilon+\varepsilon-1) \cdot \tau^{-\mu \cdot \varepsilon+\varepsilon-2}}{\left(-0.5 \cdot \tau^{-\mu \cdot \varepsilon+\varepsilon-1} \cdot(1-\mu)+1\right)^{2}}
\end{aligned}
$$

\section{A3. Determination of Equation (14)}

The profit of a expanding firm is positive, if:

$$
\begin{aligned}
\pi^{s l} & =\left(x+x^{*}\right) \cdot p-\left(x+x^{*}\right) \cdot c-(f+g) \\
& =(p-c) \cdot x-f+(p-c) \cdot x^{*} \cdot c-g
\end{aligned}
$$

(because of the zero profit condition for the small firm)

$$
=(p-c) \cdot x^{*} \cdot c-g>0
$$

Every country $i=h, f$ has the income $Y_{i}=\mu / 2$ and $n_{i}=\mu /(2 \cdot f \cdot \varepsilon)$ firms:

$$
\begin{aligned}
x^{*} & =p^{-\varepsilon} \cdot \tau^{1-\varepsilon} \cdot\left[(p \cdot \tau)^{1-\varepsilon}+p^{1-\varepsilon} \cdot n_{i}\right]^{-1} \cdot \mu \cdot Y_{i} \\
& =p^{-\varepsilon} \cdot \tau^{1-\varepsilon} \cdot\left[p^{1-\varepsilon} \cdot n_{i} \cdot\left(\frac{\tau^{1-\varepsilon}}{n_{i}}+1\right)\right]^{-1} \cdot \mu \cdot Y_{i} \\
& =p^{-1} \cdot \tau^{1-\varepsilon} \cdot \mu \cdot Y_{i}=\frac{\mu \cdot \tau^{1-\varepsilon}}{2 \cdot p \cdot n_{i}}=\frac{\tau^{1-\varepsilon} \cdot f \cdot \varepsilon}{p}
\end{aligned}
$$


(A26) in (A25) yields (14):

$$
\pi^{s l}=\frac{\tau^{1-\varepsilon} \cdot f \cdot \varepsilon}{p} \cdot(p-c)-g \equiv v^{s l} .
$$

\section{References}

Dixit, A.; Stiglitz, J. [1977], "Monopolistic Competition and Optimum Product Diversity," American Economic Review, Vol. 67; pp. 297-308.

Krugman, P. R. [1991a], Geography and Trade, Leuven.

Krugman, P. R. [1991b], "Increasing Returns and Economic Geography," Journal of Political Economy, Vol. 99 No. 3; pp. 483-499.

Krugman, P. R. [1993], "On the Number and Location of Cities," European Economic Review 37; pp. 293-98.

Varian, H. R. [1992], Microeconomic Analysis, 3. ed. New York.

Venables, A. J. [1994], "Integration and the Export Behaviour of Firms: Trade Costs, Trade Volumes and Welfare," Weltwirtschaftiches Archiv, Heft 1; pp. 118-32. 